\title{
FLEXIBLE LEARNING SPACES: THE INTEGRATION OF PEDAGOGY, PHYSICAL DESIGN, AND INSTRUCTIONAL TECHNOLOGY
}

\author{
Stern Neill and Rebecca Etheridge \\ To support pedagogical innovation, educators must reexamine physical space. This paper \\ describes a project to redesign an existing classroom into a flexible learning space. The \\ desired outcome was a classroom that would support a variety of pedagogical \\ approaches and learning experiences. The findings, based on data gathered from \\ students and faculty, indicate that the renovated classroom increases student \\ engagement, collaboration, flexibility, and learning. A flexible learning space better \\ enables innovative approaches to teaching and learning when compared to the \\ traditional classroom.
}

\section{Introduction}

The traditional classroom can be transformed through an appreciation of differing approaches to teaching and learning, application of effective physical design, and adoption of instructional technology. In leading this transformation, a team representing faculty and staff collaborated on the development, implementation, and assessment of a flexible learning space for classroom use. The overall project goal was to design a learning space through the integration of pedagogy, physical design, and instructional technology that supported a variety of pedagogical approaches and learning experiences. Achieving this goal required a flexible learning space for classroom use that would facilitate: a) a pedagogical shift from teacher-to-student, directive instruction to collaboration and self-discovery activities that involve group learning and support social learning communities; b) a physical space shift from fixed seating where furniture can sometimes be moved (as a subversive act) to flexible furniture where space can be designed for the each learning activity; and c) an instructional technology shift from centralized information technology infrastructure (i.e., multi-media presentation classrooms) to decentralized computing and networking.

From a student-centered perspective, learning is an active, participatory, experiential and cooperative process (Estes 2004; Johnson, Johnson, and Smith 1991; Wright, Bitner, and Zeithaml 1994), whereby student 
and teacher co-create the learning experience. While recent marketing education research recognizes the value of student-centered learning (e.g., Hernandez 2002; Laverie 2006; Paul and Mukhopadhyay 2001; Tanner and Roberts 1996) and providing a range of learning experiences (Karns 2006), our understanding of the role of physical space in enabling teaching and learning is limited. As the paradigm in education shifts from teacher to student and from passive to active learning (Chism and Bickford 2002), there is renewed interest in the effect of space on learning behaviors (Leung and Fung 2005; Scott-Webber 2004) and instruction (Betoret and Artiga 2004). The traditional classroom with its fixed arrangement constrains teaching and learning to one-way, linear flows. To address this connection between space and learning, a number of institutions are experimenting with flexible, networked classrooms (“Classrooms” n.d.).

Pedagogical innovation demands a space that enables exploration by both teacher and student. To be effective, this space should allow for multiple modes of instruction and learning. In developing a flexible learning space, attention was given to pedagogical, physical design, and information technology issues. Prior to implementation, the following learning space configurations were identified based on professional experience and discussions with faculty:

- Linear: Lecture, Presentation, and Video

- Horizontal: Class Discussion

- Cluster: Small Group Discussion and Activities

- Network: Decentralized Instruction

The renovated classroom allowed for up to fifty-four students and was equipped with movable tables that accommodate 6-7 students each. To provide computing and networking use without a fixed arrangement, PCs and monitors were mounted along the perimeter (see Figure 1). The room was also equipped with movable screens with whiteboard space to provide privacy and additional workspace. To facilitate lecture and presentation, equipment included an instructor PC, two video projectors, a wireless mouse, and AristoClass software.

\section{Methodology}

To assess the room's functionality, classes from a variety of academic programs were allocated to use the room (business 31\%, arts \& science 23\%, general education 23\%, social work 15\%, and computing and software systems $8 \%$ ). Faculty either requested or were assigned to the room. 
The courses also represented different student classifications (upper division 61\%, lower division $31 \%$, and graduate $8 \%)$. During the autumn and winter academic terms, thirteen classes used the room. To assess the learning space, data were gathered through surveys distributed during the last two weeks of each term. The survey data were further informed through the addition of open-ended response options as well as ongoing discussion with faculty during personal interviews and workshops. For comparison purposes, additional student data were gathered from two business capstone courses and faculty data from 18 traditional classrooms.

Information on room functionality and features was gathered by surveying faculty. Eleven faculty responded to two questions. The first question asked was, "To what extent was class time spent on the following?” Using a five-point never/very often scale, faculty reported on the frequency of lecture (linear configuration), class discussion (horizontal configuration), small group discussion (cluster configuration), and team-based activities (cluster configuration). The second question asked was, "To what extent were the following room features used?" Using the same five-point scale, faculty were asked about use of room features, i.e., instructor PC, student PCs, AristoClass software, portable room dividers, rearrangable furniture, and wireless mouse. The AristoClass software and wireless mouse require use of the instructor PC. Faculty were also asked if the room was requested or assigned to the class.

Survey data on room efficacy were gathered from eight classes representing 180 students and eight faculty. Using a seven-point, agree/ disagree scale, students were asked to evaluate the learning space compared to other campus classrooms on the following dimensions: increases my level of engagement; facilitates my working with others; allows for a variety of uses; and enhances my style of learning. Additionally, students were asked whether they would recommend the room to other students. Faculty were also asked to evaluate the learning space relative to other rooms on campus in regards to increasing student engagement; facilitating collaborative learning; allowing for a variety of uses; and enhancing their style of teaching. Additionally, faculty indicated the extent to which they would recommend the classroom to other faculty. These same questions were asked of students and faculty in traditional classrooms.

\section{Results}

Room Functionality and Features. Results from faculty about room functional usage indicated a variety of pedagogical approaches; however, there was no significant difference in room usage 
when compared to traditional classrooms for two of the three learning space configurations (see Table 1). While faculty appear to use more lecture in traditional classrooms, the use of horizontal and cluster configurations are statistically equal.

Of the room features, the movable furniture and instructor/student PCs were the most frequently used items, while other enhancements were less frequently used (see Figure 1).

Room Efficacy. Results from faculty and students indicated that the room's flexibility 1) increased student engagement, 2) facilitated collaborative learning, 3) allowed for a variety of uses, and 4) enhanced the teaching / learning styles of participants. To examine whether room feature-usage influenced student reports of room efficacy, the sample was split based on the extent to which the faculty made use of room features (i.e., high use vs. low use). A second test was performed to assess whether it mattered that faculty had requested the room or had been assigned. Third, data for the same course and instructor were compared for students in traditional and flexible classrooms. Finally, a simple regression was performed to assess the effect of student perceptions of room efficacy on student intentions to recommend the room.

The t-test results are reported in Table 2. Faculty report significantly higher ratings across all measures. For faculty who made greater use of room features, students reported stronger agreement with the statement that the room "allows for a variety of uses" (tvalue=1.90; $<<.10$ ). For faculty who requested the room, students reported significantly higher agreement with the statement that the room "facilitates my working with others" (t-value=2.92; $\mathrm{p}<.01)$. Students were also more likely to recommend the room when faculty had requested it (t-value=3.53; $\mathrm{p}<.01$ ). This suggests that faculty who requested the room had students who were more satisfied with the room.

The third test examined two student groups, one from a traditional classroom and a second from the flexible learning space. The course, teacher, and instructional approach were identical. Students used the room for the full academic term. The distinction between the two groups was the nature of the classroom (traditional vs. flexible). Across all measures of room efficacy, students in the flexible classroom reported higher values. The results confirm that while the pedagogy does not differ student perceptions are that engagement, collaboration, flexibility, and learning are enhanced in the flexible learning space.

The regression results, as reported in Table 3, suggest that three of the efficacy measures are 
related to whether students would recommend the room. Specifically, students who agreed to recommend the room viewed it as better at facilitating their working with others, allowing for a variety of uses, and enhancing their particular style of learning. The room's ability to increase engagement was not a significant factor in the regression variate.

\section{Discussion}

As faculty explore innovative approaches to teaching and learning, attention should be given to

physical space. Environmental psychologists recognize that physical space can influence behavior in both positive and negative ways (Mehrabian and Russell 1974). This

study examines how a flexible learning space increases student engagement, collaboration, flexibility, and learning. While students benefit from a range of learning experiences (Karns 2006), the traditional classroom, with its fixed seating arrangement and singular focus on the instructor, is best-suited for lecture. With faculty implementing alternative teaching and learning strategies, a traditional space constrains the effectiveness of more student-centered approaches. Learning that is active, participatory, experiential and cooperative requires a flexible space. In this way, physical space is viewed as an agent of change (Oblinger 2006).

The findings from this study suggest that faculty use multiple approaches (i.e., linear, horizontal, and cluster configurations) in both traditional and flexible classrooms; however, student perceptions of each room's effectiveness differ. While the results do not support that the room changes faculty behavior, the flexible learning space is viewed as contributing positively to student engagement, collaboration, flexibility, and learning. Faculty report substantial higher benefits to the room than students, which may be because their experience

allows them to better recognize the room's efficacy. Students in the flexible learning space recognize that the room allows for a variety of uses. This may provide students the freedom to explore different approaches to developing understanding, meaning, and / or solutions.

Faculty that requested the flexible learning space understand its features and seem motivated to use them. This conclusion is supported by student and faculty responses. For faculty who requested the room, students reported higher levels of collaborative learning and were also more likely to recommend the room. Faculty who requested the room may have done so with the understanding that it would facilitate working with others. Additionally, faculty offered comments on the room's flexibility: 
- "ease in arranging room for experiential assignments"

- "flexibility [for] small group work with computers"

- "offers flexibility [which] is great for courses where participation is important"

- "students are empowered to configure the room in a manner that best suits their learning in realtime.”

Overall, student satisfaction with the room, as measured by willingness to recommend it to others, was influenced by the room's ability to facilitate working with others, allow for a variety of uses, and enhance a student's particular style of learning.

One barrier to implementation was getting faculty and students comfortable with moving the furniture. As a solution, one faculty member stated, "I arrive a few minutes early and have 'trained' the class to arrange the room in a U-shape at the start of class ... [for the second half,] students break out into computer simulation groups....” Another faculty supported this view, stating, "By modifying the room to match the mode of instruction, students are actively involved in learning." A second barrier was the placement of the instructor PC, which constrained instruction to a fixed position at the front of the room. A portable instructor PC with wireless access to video displays would allow for more decentralized instruction.

In addition to redesigning space, the experience suggests a number of enhancements. First, a communication strategy is needed to build awareness of the room and train faculty on room features. This would allow interested faculty to use the room and to make better use of its functionality and features. Second, room enhancements should be considered that give the instructor greater freedom of movement and an ability to engage in decentralized instruction. Finally, faculty forums should be establised so that instructions can share best practices This study has limitations that should be considered when interpreting the findings. While the study does capture room efficacy, it does not assess whether the room changed behavior or impacted learning. With experience using the room, faculty may begin to explore new pedagogical approaches in preparing for future courses, which opens up avenues for further research. Additionally, future research could directly examine the effect of the room on student learning behaviors and outcomes. The room's fixed instructor PC precluded decentralized instruction, which resulted in a network configuration not being tested. Future research might examine the effect of allowing the instructor to move about the room. Finally, the use of single 
item measures prevented assessment of measurement reliability. Research using multi-item measure would allow for a rigorous test of psychometric properties.

\section{Conclusion}

Student-centered approaches to learning require a physical space that adapts to learner demands. Using modular furniture and accessible information technology better supports alternative approaches to teaching and learning. As instruction moves toward co-creation of the learning experience, the flexible, networked classroom provides an appropriate physical setting. Investment in flexible learning space design supports students and faculty and reinforces institutional commitment to educational excellence.

\section{References}

Betoret, Fernando Doménech and Amparo Gómez Artiga (2004), “Trainee Teachers’ Conceptions of Teaching and Learning, Classroom Layout and Exam Design,” Educational Studies, 30 (4), 355-372.

Chism, Nancy Van Note and Deborah J. Bickford (2002), "Improving the Environment for Learning: An Expanded Agenda," in The Importance of Physical Space in Creating Supportive Learning Environments: New Directions in Teaching and Learning, No. 92, Nancy Van Note Chism and Deborah J. Bickford, eds., San Francisco: Jossey-Bass.

Classrooms (n.d.), Retrieved February 3, 2006, from http:// www.ncsu.edu/per/SCALEUP/Classrooms.html.

Estes, Cheryl A. (2004), "Promoting Student-Centered Learning in Experiential Education,” Journal of Experiential Education, 27 (2), 141-160.

Hernandez, Sigfredo A. (2002), “Team Learning in a Marketing Principles Course: Cooperative Structures that Facilitate Active Learning and Higher Level Thinking,” Journal of Marketing Education, 24 (1), 73- 85.

Johnson, David W., Roger T. Johnson, and Karl A. Smith (1991), Active Learning: Cooperation in the College Classroom, Edina, MN: Interaction Book Company.

Karns, Gary L. (2006), "Learning Style Differences in the Perceived Effectiveness of Learning Activities,” Journal of Marketing Education, 28 (1), 56-63. 
Laverie, Debra A. (2006), "In-Class Active Cooperative Learning: A Way to Build Knowledge and Skills in Marketing Courses,” Marketing Education Review, 16 (2), 59-76.

Leung, Mei-yung and Ivan Fung (2005), "Enhancement of Classroom Facilities of Primary Schools and Its Impact on Learning Behaviors of Students,” Facilities, 23 (13/14), 585-594.

Mehrabian, Albert and James A. Russell (1974), An Approach to Environmental Psychology, Cambridge, MA: M.I.T. Press.

Oblinger, Diana G. (2006), “Space as a Change Agent,” in Learning Space Design, Diana G. Oblinger, ed., Boulder, CO: Educause.

Paul, Pallab and Kausiki Mukhopadhyay (2001), “Using Information Technology for Active

Learning in International Business Education,” Marketing Education Review, 11 (3), 81-89.

Scott-Webber, Lennie (2004), In Sync: Environment Behavior Research and the Design of Learning Spaces, Ann Arbor, MI: Society for College and University Planning.

Tanner Jr., John F. and James A. Roberts (1996), “Active Learning: Students as Teachers,” Marketing Education Review, 6 (1), 41-46.

Wright, Lauren K., Mary Jo Bitner, and Valerie A. Zeithaml (1994), "Paradigm Shifts in

Business Education: Using Active Learning to Deliver Services Marketing Content,” Journal of Marketing Education, 16 (3), 5-19. 
Figure 1

Room Configuration

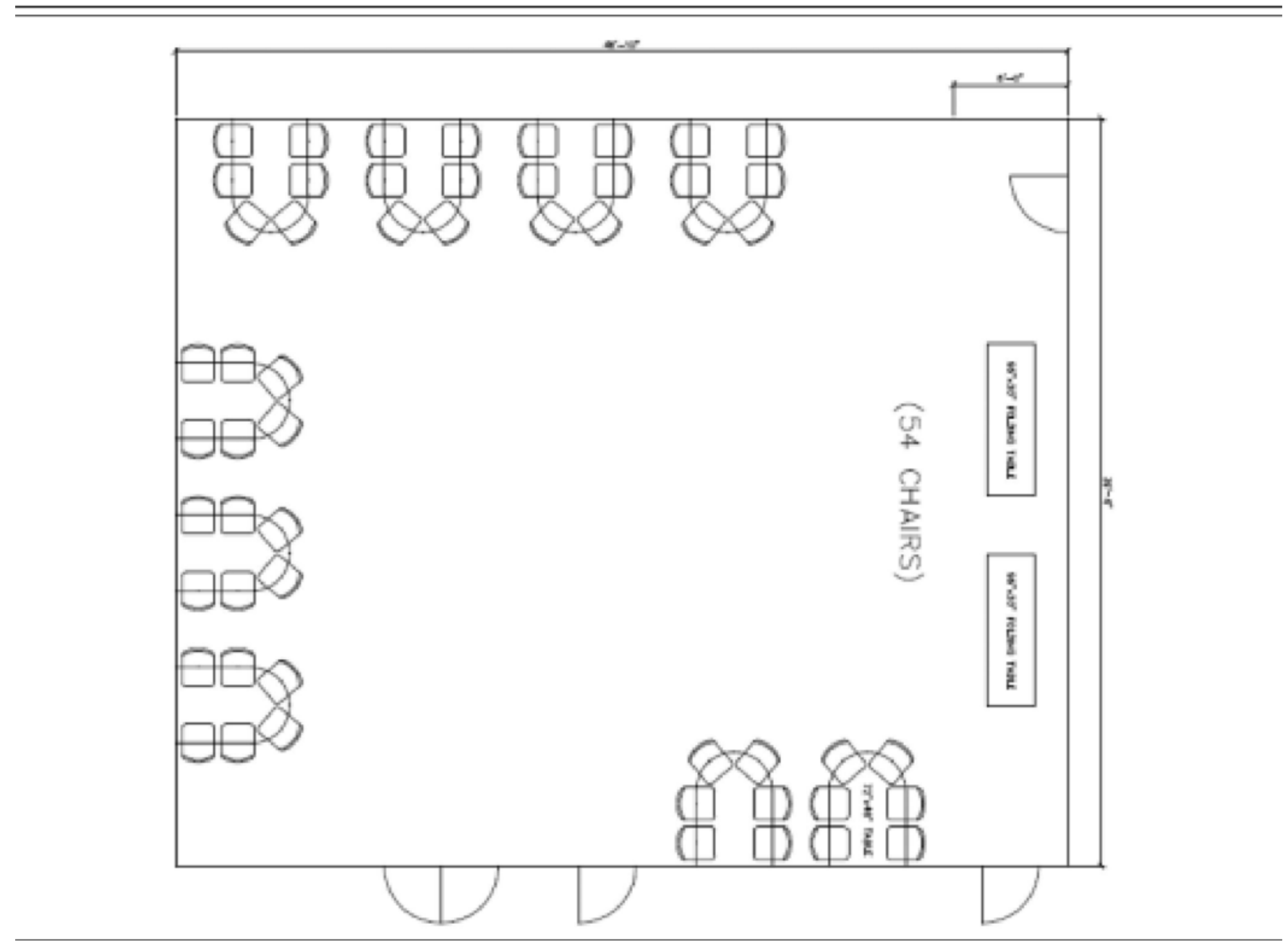


Table 1

Room Function Use: Means (Standard Deviations) and t-values

\begin{tabular}{lcccc} 
& & & & Spring 2008 \\
Cluster: \\
Linear. & Hocture & Cluster: & $\begin{array}{c}\text { Clum-based } \\
\text { Activities }\end{array}$ \\
\hline Traditional & 4.17 & 3.47 & $\begin{array}{c}\text { Small Group } \\
\text { Discussion }\end{array}$ & 2.78 \\
Flexible & $(0.86)$ & $(1.23)$ & 2.89 & $(1.21)$ \\
& 3.64 & 3.91 & $(1.13)$ & 3.27 \\
t-value & $(0.67)$ & $(0.70)$ & 3.55 & $(1.35)$ \\
& $1.74^{\mathrm{a}}$ & 1.07 & $(1.13)$ & 1.02
\end{tabular}

Figure 2

Room Feature Use

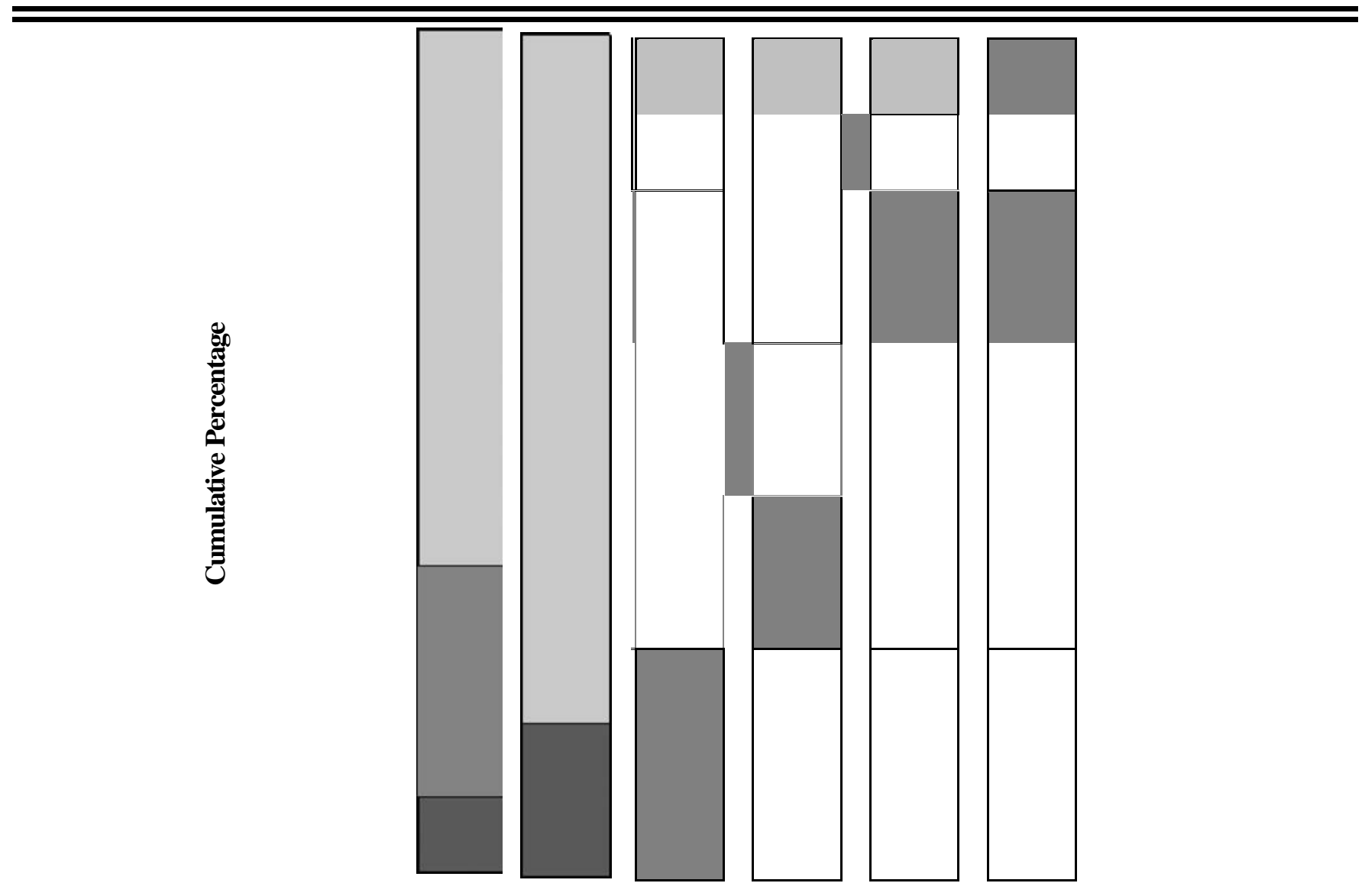


Table 2

Room Efficacy: Means (Standard Deviations) and t-values

\begin{tabular}{|c|c|c|c|c|c|}
\hline \multicolumn{6}{|l|}{ Full Sample } \\
\hline $\begin{array}{l}\text { Faculty } \\
\text { t-value }\end{array}$ & $\begin{array}{c}6.33 \\
(0.82) \\
2.16^{\mathrm{b}} \\
\end{array}$ & $\begin{array}{c}6.83 \\
(0.41) \\
2.50^{\mathrm{b}} \\
\end{array}$ & $\begin{array}{c}6.83 \\
(0.41) \\
2.10^{\mathrm{b}} \\
\end{array}$ & $\begin{array}{c}6.83 \\
(0.41) \\
2.96^{\mathrm{C}} \\
\end{array}$ & $\begin{array}{c}7.00 \\
(0.00) \\
2.50^{\mathrm{b}} \\
\end{array}$ \\
\hline \multicolumn{6}{|l|}{ Feature Use } \\
\hline Low Use & $\begin{array}{c}4.79 \\
(1.70)\end{array}$ & $\begin{array}{r}5.24 \\
(1.42)\end{array}$ & $\begin{array}{r}5.38 \\
(1.44)\end{array}$ & $\begin{array}{r}4.74 \\
(1.52)\end{array}$ & $\begin{array}{r}5.39 \\
(1.43)\end{array}$ \\
\hline High Use & $\begin{array}{c}5.19 \\
(1.36)\end{array}$ & $\begin{array}{r}5.48 \\
(1.47)\end{array}$ & $\begin{array}{r}5.88 \\
(1.32)\end{array}$ & $\begin{array}{r}5.16 \\
(1.53)\end{array}$ & $\begin{array}{r}5.66 \\
(1.44)\end{array}$ \\
\hline \multicolumn{6}{|c|}{ Room Assignment } \\
\hline Assigned & $\begin{array}{c}4.92 \\
(1.61)\end{array}$ & $\begin{array}{r}4.85 \\
(1.74)\end{array}$ & $\begin{array}{r}5.54 \\
(1.60)\end{array}$ & $\begin{array}{r}4.85 \\
(1.66)\end{array}$ & $\begin{array}{r}4.92 \\
(1.71)\end{array}$ \\
\hline Requested & $\begin{array}{c}5.17 \\
(1.39)\end{array}$ & $\begin{array}{c}5.61 \\
(1.31)\end{array}$ & $\begin{array}{r}5.85 \\
(1.27)\end{array}$ & $\begin{array}{r}5.14 \\
(1.49)\end{array}$ & $\begin{array}{r}5.83 \\
(1.27)\end{array}$ \\
\hline t-value & 0.92 & $2.92^{\mathrm{c}}$ & 1.24 & 1.05 & $3.53^{\mathrm{c}}$ \\
\hline \multicolumn{6}{|c|}{ Business Capstone } \\
\hline Traditional & $\begin{array}{c}3.45 \\
(1.43)\end{array}$ & $\begin{array}{r}3.32 \\
(1.45)\end{array}$ & $\begin{array}{r}2.79 \\
(1.52)\end{array}$ & $\begin{array}{r}3.23 \\
(1.41)\end{array}$ & $\begin{array}{r}3.16 \\
(1.47)\end{array}$ \\
\hline
\end{tabular}


Table 3

Regression Results of Standardized Estimates with Room Recommendation as the

Dependent Variable

Independent Variables

Beta t-value

Engagement

0.09

1.21

Collaboration

$0.27^{\mathrm{C}}$

$0.17^{\mathrm{c}}$

3.39

Flexibility

Learning

$0.40^{\mathrm{c}}$

2.61

Adjusted R2

F-value

.70

$104.81^{\mathrm{C}}$ 